\title{
Dynamics of Hypoxia, Proliferation and Apoptosis after Irradiation in a Murine Tumor Model
}

\author{
Author(s) :Anna S. E. Ljungkvist, Johan Bussink, Johannes H. A M. Kaanders, Nicole E. Wiedenmann, \\ Renske Vlasman, and Albert J. van der Kogel \\ Source: Radiation Research, 165(3):326-336. 2006. \\ Published By: Radiation Research Society \\ DOI: http://dx.doi.org/10.1667/RR3515.1 \\ URL: http://www.bioone.org/doi/full/10.1667/RR3515.1
}

BioOne (www.bioone.org) is a nonprofit, online aggregation of core research in the biological, ecological, and environmental sciences. BioOne provides a sustainable online platform for over 170 journals and books published by nonprofit societies, associations, museums, institutions, and presses.

Your use of this PDF, the BioOne Web site, and all posted and associated content indicates your acceptance of BioOne's Terms of Use, available at www.bioone.org/page/terms_of_use.

Usage of BioOne content is strictly limited to personal, educational, and non-commercial use. Commercial inquiries or rights and permissions requests should be directed to the individual publisher as copyright holder. 


\title{
Dynamics of Hypoxia, Proliferation and Apoptosis after Irradiation in a Murine Tumor Model
}

\author{
Anna S. E. Ljungkvist, ${ }^{a, 1}$ Johan Bussink, ${ }^{a}$ Johannes H. A. M. Kaanders, ${ }^{a}$ Nicole E. Wiedenmann, ${ }^{b}$ \\ Renske Vlasman ${ }^{a}$ and Albert J. van der Kogel ${ }^{a}$ \\ ${ }^{a}$ Department of Radiation Oncology, Radboud University Nijmegen Medical Centre, Nijmegen, the Netherlands; and \\ ${ }^{b}$ Department of Radiation Oncology, Klinikum rechts der Isar, Technical University of Munich, 81675 Munich, Germany
}

Ljungkvist, A. S. E., Bussink, J., Kaanders, J. H. A. M., Wiedenmann, N. E., Vlasman, R. and van der Kogel, A. J. Dynamics of Hypoxia, Proliferation and Apoptosis after Irradiation in a Murine Tumor Model. Radiat. Res. 165, 326336 (2006).

Proliferation and hypoxia affect the efficacy of radiotherapy, but radiation by itself also affects the tumor microenvironment. The purpose of this study was to analyze temporal and spatial changes in hypoxia, proliferation and apoptosis after irradiation $(20 \mathrm{~Gy})$ in cells of a murine adenocarcinoma tumor line (C38). The hypoxia marker pimonidazole was injected $1 \mathrm{~h}$ before irradiation to label cells that were hypoxic at the time of irradiation. The second hypoxia marker, CCI$103 \mathrm{~F}$, and the proliferation marker BrdUrd were given at 4 , 8 and $28 \mathrm{~h}$ after irradiation. Apoptosis was detected by means of activated caspase 3 staining. After immunohistochemical staining, the tumor sections were scanned and analyzed with a semiautomatic image analysis system. The hypoxic fraction decreased from $22 \%$ in unirradiated tumors to $8 \%$ at both 8 $\mathrm{h}$ and $28 \mathrm{~h}$ after treatment $(P<0.01)$. Radiation did not significantly affect the fraction of perfused vessels, which was $95 \%$ in unirradiated tumors and $90 \%$ after treatment. At 8 $h$ after irradiation, minimum values for the BrdUrd labeling index (LI) and maximum levels of apoptosis were detected. At $28 \mathrm{~h}$ after treatment, the BrdUrd labeling and density of apoptotic cells had returned to pretreatment levels. At this time, the cell density had decreased to $55 \%$ of the initial value and a proportion of the cells that were hypoxic at the time of irradiation (pimonidazole-stained) were proliferating (BrdUrd-labeled). These data indicate an increase in tumor oxygenation after irradiation. In addition, a decreased tumor cell density without a significant change in tumor blood perfusion (Hoechst labeling) was observed. Therefore, it is likely that in this tumor model the decrease in tumor cell hypoxia was caused by reduced oxygen consumption. @ 2006 by Radiation Research Society

\section{INTRODUCTION}

The tumor microenvironment is characterized by an abnormal and heterogeneously organized tumor vasculature

\footnotetext{
${ }^{1}$ Address for correspondence: Department of Radiation Oncology, POB 9101, Radboud University Nijmegen Medical Centre, 6500 HB Nijmegen, The Netherlands; e-mail: A.Ljungkvist@rther.umcn.nl.
}

$(1-4)$. There is often an imbalance between tumor cell proliferation and cell death, resulting in uncontrolled tumor growth. Tumor cell proliferation is generally decreasing at increasing distances from blood vessels. Frequently tumor cells outgrow the vascular supply, resulting in tumor cell hypoxia, which is often found at greater distances from blood vessels or surrounding regions of tumor necrosis (4$8)$. In addition, fluctuations in tumor blood flow result in different gradients of oxygen and nutrients $(9,10)$. Consequently, in many tumors, the hypoxic cell population is heterogeneous with respect to the level and duration of hypoxia. Hypoxic tumor cells can promote malignant progression by secretion of growth factors that stimulate angiogenesis, cell proliferation and metastasis $(11,12)$. The unique features of the tumor microenvironment such as proliferation, hypoxia and apoptosis can be exploited as specific targets for anti-cancer treatments, and the relevance of these parameters for radiotherapy is well recognized.

Loss of local control with increasing overall treatment time has demonstrated the importance of tumor cell proliferation in patients with head and neck and cervical cancer who are treated with radiotherapy (13-17). Continuous hyperfractionated accelerated radiotherapy (CHART) has shown that by reducing the overall treatment time, a significant gain can be obtained for non-small cell lung cancer (18). Also, in head and neck cancer, improved local control with accelerated schedules has been demonstrated in randomized trials $(19,20)$. For head and neck cancer, histological proliferation patterns have shown a better predictive power for treatment outcome than either labeling index or potential doubling time alone (21). This indicates that simultaneous assessment of different parameters of the tumor microenvironment may improve the development of predictive assays.

Tumor cell hypoxia is predictive for local control and survival after surgery or radiotherapy for carcinomas of the head and neck and uterine cervix (22-25). It is well known that radiotherapy is less effective under hypoxic conditions than under well-oxygenated conditions. Moreover, radiation by itself also affects tumor hypoxia and cell kinetics. Reoxygenation has been reported to occur within $24-72 \mathrm{~h}$ after 
treatment, and it may affect the efficacy of the subsequent fraction in a conventional fractionation schedule (26-29). Indirect evidence for a rapid increase in the oxygen tension after irradiation has been obtained with radiobiological assays for several tumor lines $(26,30)$. Measurements of $p \mathrm{O}_{2}$ have shown that early reoxygenation occurs within 3-6 h after irradiation. It was hypothesized that this is caused by both decreased oxygen consumption and increased oxygen delivery $(28,31)$.

Dynamic processes in the tumor microenvironment can be visualized with immunohistochemical staining of endogenous and exogenous markers, which can be analyzed in relation to tumor vasculature with microregional imaging techniques (4, 7, 32-34). Several exogenous markers of hypoxia such as pimonidazole, EF5 and CCI-103F are available $(7,8,32,35)$. With consecutive injection of two hypoxic cell markers, pimonidazole and CCI-103F, treatment-induced changes in hypoxia can be measured, allowing each tumor to serve as its own control (36-38). For detection of proliferation, the exogenous markers bromodeoxyuridine (BrdUrd) and iododeoxyuridine (IdUrd) can be used $(4,39,40)$.

In this study, spatial and temporal changes in hypoxia, proliferation and apoptosis were studied after a single radiation dose of $20 \mathrm{~Gy}$ in the murine tumor line C38. Sequential injection of pimonidazole and CCI-103F was used to detect changes in hypoxia during the first $28 \mathrm{~h}$ after irradiation. Changes in tumor cell proliferation (BrdUrd) and apoptosis (activated caspase 3) were analyzed in relation to the cells that were hypoxic at the time of irradiation.

\section{MATERIALS AND METHODS}

\section{Tumor Model and Markers of Hypoxia, Perfusion and Proliferation}

As the tumor model, cells of the murine colon adenocarcinoma line C38 grown in C57BL/6 mice were used (41). Small tumor pieces were transplanted subcutaneously into the right hind leg of anesthetized mice. Experiments started when the tumors reached a mean diameter of 6-8 $\mathrm{mm}(n=26)$. All mice were kept at the Central Animal Laboratory in accordance with institutional guidelines. Approval of the local ethical committee for animal use was obtained for all experiments.

For detection of changes in hypoxia, the 2-nitroimidazoles pimonidazole hydrochloride (1-[(2-hydroxy-3-piperidinyl)propyl]-2-nitroimidazole hydrochloride) (Chemicon International, Inc., Temecula, CA) and CCI103F [1-(2-hydroxy-3-hexafluoroisopropoxy-propyl)-2-nitroimidazole; a gift from J. A. Raleigh, Department of Radiation Oncology, University of North Carolina, Chapel Hill, NC] (42) were used at a dose of $80 \mathrm{mg} /$ $\mathrm{kg}$. These bioreductive compounds differ only in the immunologically detectable side chain. Double staining of consecutively injected markers in nontreated tumors results in a good spatial match, although pimonidazole generally covers a slightly larger area than CCI-103F $(36,37)$. Pimonidazole was dissolved in saline and injected intraperitoneally (i.p.) in a volume of $0.5 \mathrm{ml}$. A mixture of CCI-103F and the proliferation marker BrdUrd $(50 \mathrm{mg} / \mathrm{kg})$ dissolved in $10 \%$ DMSO and $90 \%$ peanut oil was given i.p. in a volume of $0.5 \mathrm{ml}$. As a perfusion marker, Hoechst 33342 (Sigma) was given intravenously at a dose of $15 \mathrm{mg} / \mathrm{kg}$ in $0.1 \mathrm{ml}$ saline.

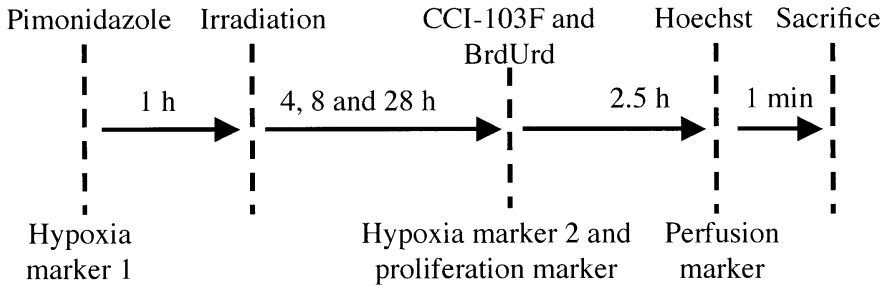

FIG. 1. Treatment schedule and experimental design. See the text for details.

\section{Irradiation and Experimental Setup}

The irradiation setup has been described previously (27). The animals were irradiated under anesthesia with an irradiation field of $3 \times 2 \mathrm{~cm}$ on the tumor-bearing hind leg. A total dose of $20 \mathrm{~Gy}$ was given with a 16 MV photon beam at a dose rate of 2 Gy per minute.

Pimonidazole, which is very stable once it is reduced and bound in hypoxic cells $(37,43)$, was given $1 \mathrm{~h}$ before irradiation followed by the mixture of CCI-103F and BrdUrd at 4, 8 and $28 \mathrm{~h}$ after irradiation (Fig. 1). At $2.5 \mathrm{~h}$ after injection of CCI-103F, the perfusion marker Hoechst 33342 was injected. One minute later, the animals were killed humanely and the tumors were snap-frozen in liquid nitrogen. For each time, a control group kept under ambient conditions was injected with markers as described above. Four to five animals were used in each group.

\section{Immunohistochemistry}

Frozen sections $(5 \mu \mathrm{m})$ were fixed in acetone $\left(4^{\circ} \mathrm{C}\right)$, and the Hoechst 33342 signal was recorded on air-dried tissue sections. After rehydration, three consecutive tumor sections were triple-stained for pimonidazole and vasculature in combination with CCI-103F, BrdUrd or activated caspase 3.

Pimonidazole was detected with a polyclonal rabbit anti-pimonidazole (a gift from J. A. Raleigh) (44) and donkey anti-rabbit F(ab')2Alexa488 (Molecular Probes, Eugene, OR). For staining of the blood vessels, undiluted 9F1 supernatant [rat monoclonal to mouse endothelium, (Department of Pathology, Radboud University Nijmegen Medical Centre, Nijmegen, The Netherlands)] and chicken anti-rat ALEXA647 (Molecular Probes) were used. CCI-103F was detected with a polyclonal rabbit antiCCI-103F antibody (a gift from J. A. Raleigh) (45), followed with BiotinSP-conjugated donkey anti-rabbit $\mathrm{F}\left(\mathrm{ab}^{\prime}\right)_{2}$ and $\mathrm{Cy} 3$-conjugated mouse anti-biotin antibody (Jackson Immuno Research Laboratories, West Grove, PA). For detection of apoptosis, rabbit anti-active caspase 3 (R\&D Systems Inc. Minneapolis, MN) was used, followed by donkey anti-rabbit Fab_biotin (Jackson Immuno Research). Subsequently, streptavidin-Cy3 and goat anti-rabbit Fab_Cy3 (Jackson Immuno Research) were used. For BrdUrd staining, the tumor sections were first denatured in $0.2 \mathrm{~N} \mathrm{HCl}$ for $10 \mathrm{~min}$ followed by neutralization for $10 \mathrm{~min}$ in $0.1 \mathrm{M}$ borax. BrdUrd was visualized with sheep anti-BrdU IgG (Abcam Ltd., Cambridge, UK) and donkey anti-sheep $\mathrm{F}\left(\mathrm{ab}^{\prime}\right)$ 2-Cy3 (Jackson Immuno Research). For analysis of the BrdUrd labeling index, all nuclei were stained with propidium iodide (Molecular Probes).

\section{Image Acquisition, Processing and Analysis}

The tumor sections were mounted with Fluorostab (ICN Pharmaceuticals, Inc.) and analyzed quantitatively with a semi-automatic image recording system as described previously (46). Using different filter sets, multiple scans at $100 \times$ magnification yielded composite images with the two hypoxia markers. At $200 \times$ magnification, composite images with pimonidazole and either proliferation or apoptosis were obtained. The grayscale images were thresholded into binary images $(37,47)$, which were used for quantitative analysis of spatial relationships between proliferation, hypoxia and apoptosis. A consecutive H\&E-stained tumor section was used to define the tumor area excluding non-tumor tissue, necrosis and staining artifacts. 
The hypoxic fractions of pimonidazole (HF-pimo) and CCI-103F (HF$\mathrm{CCI}$ ) were defined as the areas positive for pimonidazole or CCI-103F divided by the total tumor area. The fraction of perfused vessels (PF) was defined as the number of pixels positive for both vasculature (9F1) and perfusion (Hoechst 33342) divided by the total number of vascular pixels. The relative cell density was defined as the number of pixels positive for propidium iodide divided by the total tumor area. The relative cell density of proliferating cells was calculated as the number of BrdUrdpositive pixels divided by the total tumor area. The labeling index (LI) was calculated as the BrdUrd-labeled pixels divided by the propidium iodide (all nuclei)-labeled pixels. The densities of apoptotic cells were defined as the number of objects positive for activated caspase 3 divided by (1) the tumor area, (2) the pimonidazole positive area, and (3) the non-pimonidazole-stained tumor area, respectively. The tumors in all control groups were pooled for analysis of perfusion, proliferation and apoptosis since labeling of these markers occurred at a constant interval relative to tumor harvest.

\section{Statistics}

The statistical analyses were done on a Macintosh computer using GraphPad Prism version 4 (GraphPad Software, San Diego, CA). For all parameters, a comparison of control and irradiated tumors was made with ANOVA followed by the Tukey test. A $P$ value below or equal to 0.05 was considered statistically significant.

\section{RESULTS}

\section{Dynamics of Hypoxia in Unirradiated Compared to Irradiated Tumors}

The pseudo-colored binary images in Fig. 2 show the spatial distribution of the first hypoxia marker pimonidazole (green) and the second hypoxia marker CCI-103F (red) relative to the tumor vasculature (white). The yellow color reflects overlap of the two hypoxia markers. The time between injection of CCI-103F and harvest was always 2.5 $\mathrm{h}$, but the interval between irradiation and CCI-103F injection varied (4, 8 and $28 \mathrm{~h})$. Pimonidazole was always given $1 \mathrm{~h}$ before irradiation. Thus CCI-103F reflects the hypoxic status at various times after irradiation, whereas pimonidazole identifies cells that were hypoxic at the time of irradiation.

There was a good spatial co-localization of the two hypoxia markers in the 4-h group in unirradiated tumors and the fraction of CCI-103F stained cells was similar in all untreated tumors (Fig. 2). With increasing intervals between the hypoxia marker injections, the pimonidazolestained cells (green) started to disappear and pimonidazolelabeled cell fragments appeared in the necrotic regions. Bioreductive hypoxia markers can be reduced and bound only in viable cells (intact and metabolically active). Therefore, elimination of pimonidazole-positive cells reflects clearance of cells that have died in the interval between pimonidazole injection and tumor harvest, reflecting the turnover of initially hypoxic cells (37). This was illustrated as a reduction of the tumor areas showing co-localization of pimonidazole and CCI-103F (yellow). The first sign of elimination of pimonidazole-labeled cells was found at $8 \mathrm{~h}$ and was more pronounced at $28 \mathrm{~h}$. At the latter time, a "red margin" of one to two cell layers labeled only with
CCI-103F appeared at the vessel side of the hypoxic areas. Those cells were not yet hypoxic at the time of the first hypoxia marker injection but had migrated away from the blood vessels within this period. The remains of dead cells appeared as cell debris labeled with pimonidazole in the necrotic tumor areas. Figure 2 shows the tumor sections after quantification and exclusion of cell debris from the images. In the untreated tumors, the hypoxic fraction based on pimonidazole staining decreased from $30 \%$ in the 4-h group to $18 \%$ in the 28 -h group $(P<0.01)$, while the mean hypoxic fraction based on CCI-103F staining did not differ significantly in any of the control tumors (Fig. 3).

The first hypoxia marker, pimonidazole, was given $1 \mathrm{~h}$ before irradiation. Since the half-life of pimonidazole in murine blood plasma is around $30 \mathrm{~min}$ (48), the majority of pimonidazole-labeled cells were hypoxic during irradiation. Due to intertumor heterogeneities between untreated and irradiated tumors in the 4-h group, there was a small variation in the mean hypoxic fractions of pimonidazole. Nevertheless, the spatial distribution and the relative differences in hypoxic fraction as measured by the first and second hypoxia marker were identical in untreated and irradiated tumors (Figs. 2 and 3). At 8 and $28 \mathrm{~h}$ after irradiation, there was a clear decrease of the second hypoxia marker CCI-103F (red) compared to the first marker pimonidazole (green). This is illustrated in Fig. 2 as a decrease in co-localization of both hypoxia markers (yellow) resulting in areas stained with only the first hypoxia marker, pimonidazole (green). The mean hypoxic fractions of CCI$103 \mathrm{~F}$ decreased from $22 \%$ in unirradiated tumors to $8 \%$ at $8 \mathrm{~h}$ after irradiation $(P<0.001)$ and to $8 \%$ at $28 \mathrm{~h}$ after irradiation $(P<0.001)$ (Fig. 3). Thus the hypoxic fraction decreased by a factor of three after irradiation, which is in accordance with treatments with $10 \mathrm{~Gy}$ in cells of the SCVII $(28,49)$ and SCCNij3 (27) tumor lines. In contrast to untreated tumors, in the irradiated animals, there was no significant change in hypoxic fractions of pimonidazole for the various times (Fig. 3). The fraction of perfused blood vessels was $95 \%$ (75-99) in unirradiated tumors and $90 \%$ (71-96) after irradiation. Thus irradiation resulted in an increase in the oxygenation status (decreased hypoxic fractions of CCI-103F) and a decreased turnover rate of initially hypoxic cells (unchanged hypoxic fractions of pimonidazole), while the fraction of functional blood vessels was unaffected.

\section{Radiation-Induced Changes in Proliferation}

Radiation-induced changes in tumor cell proliferation were analyzed by means of BrdUrd administration at different times after treatment. The left panels of Fig. 4 show the spatial distribution of BrdUrd (red) in relation to the oxygenation status at the time of irradiation (pimonidazole, green) and vasculature (white). At 4 and $8 \mathrm{~h}$ after treatment, the BrdUrd labeling could not be analyzed quantitatively due to extensive cell death (H\&E-stained sections, Fig. 4). 
4h Unirradiated

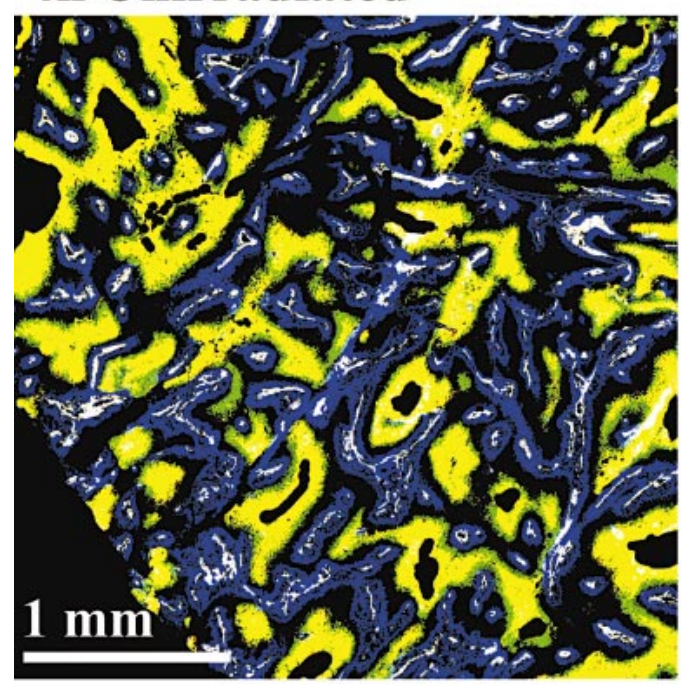

8h Unirradiated

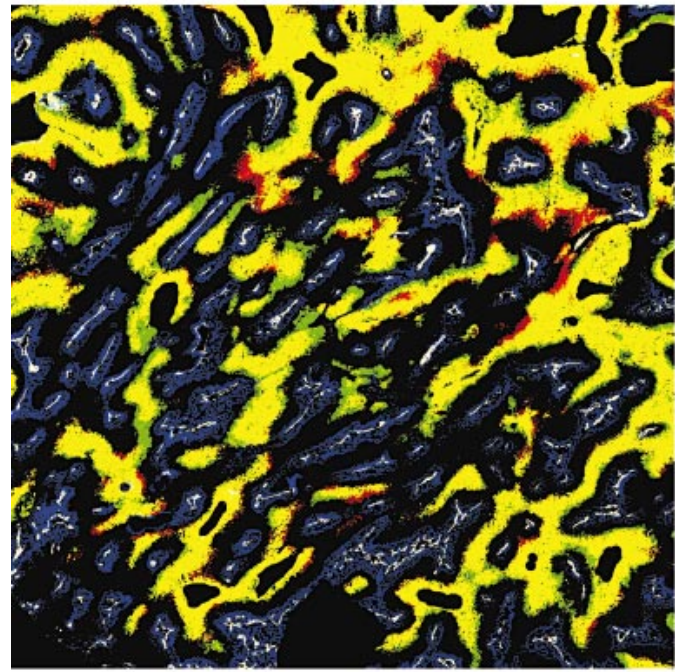

28h Unirradiated

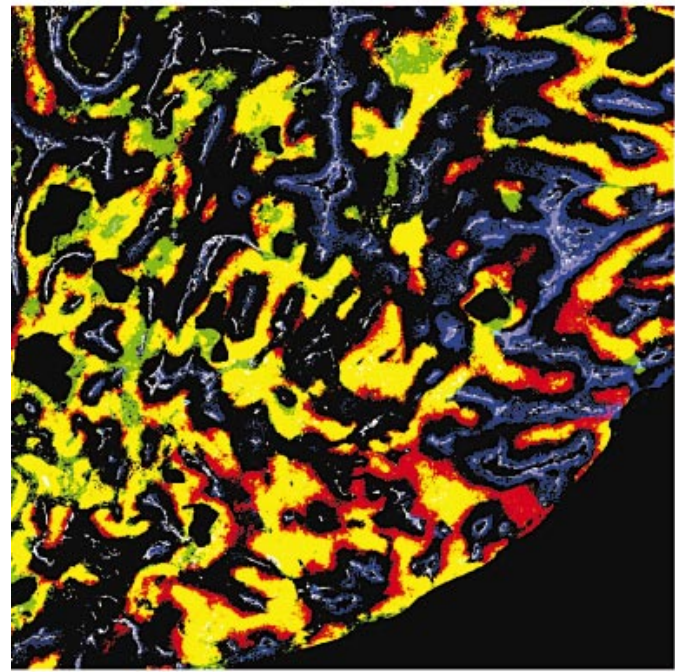

4h Irradiated

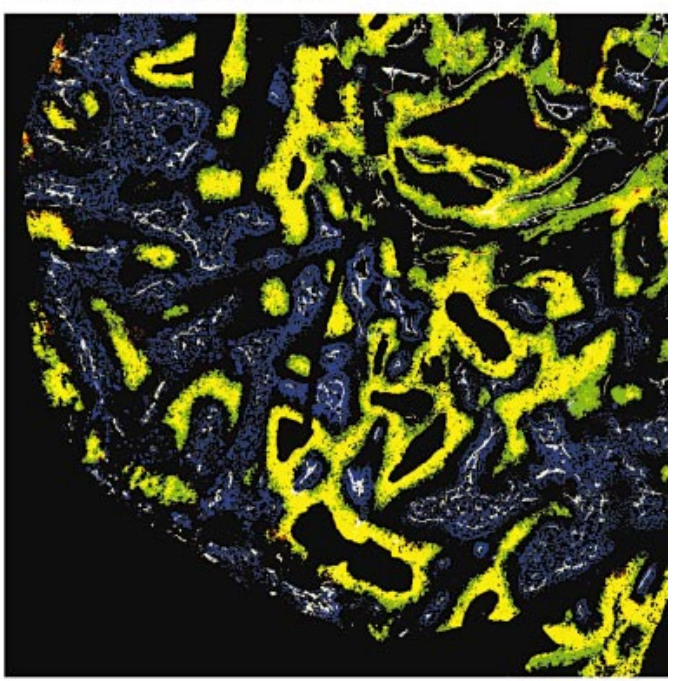

8h Irradiated

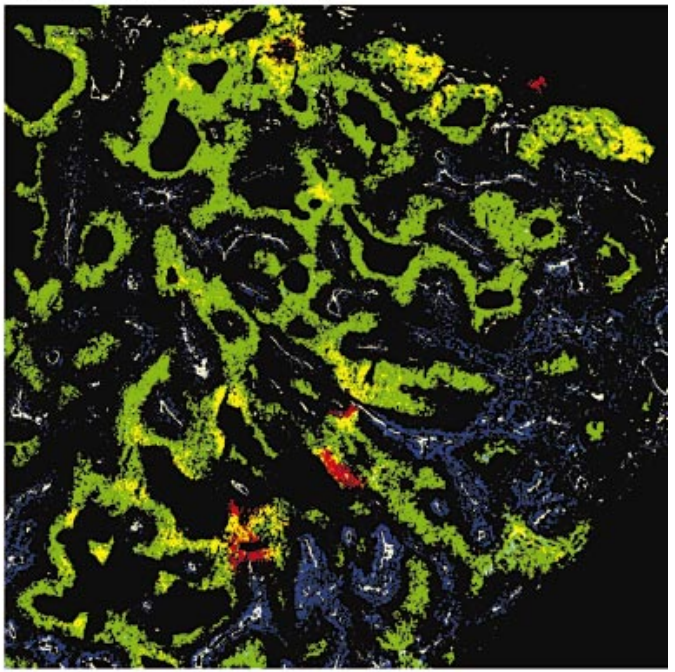

28h Irradiated

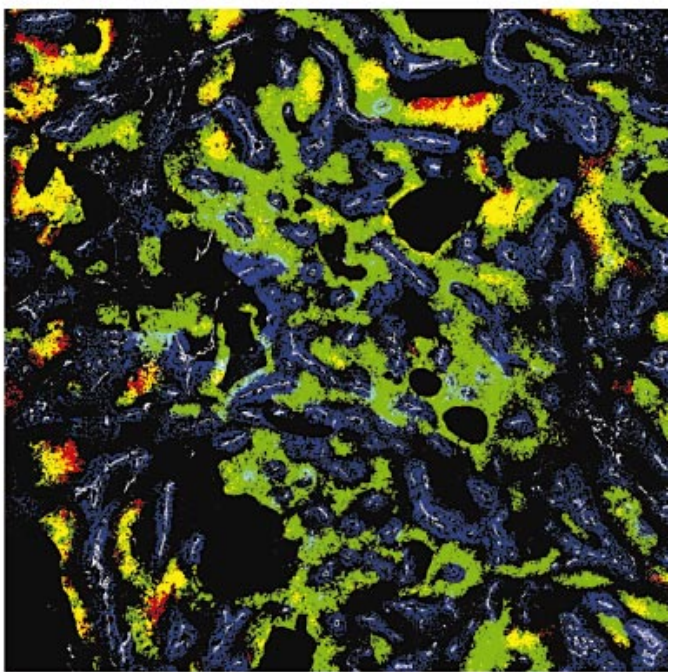

FIG. 2. Composite binary images of sections of the murine tumor C38 (colon adenocarcinoma). Vasculature (9F1, white), perfusion marker (Hoechst 33342 , blue), first hypoxia marker (pimonidazole, green), and the second hypoxia marker (CCI-103F, red); overlap of the two hypoxia markers is yellow. The left panel shows control tumors and the right shows tumors treated with a single dose of X rays (20 Gy). The intervals between irradiation and harvest are indicated in the images. Pimonidazole shows the initially hypoxic cell population and CCI-103F shows the cell population that was hypoxic at time of harvest. Original magnification $100 \times$, scale bar $=1 \mathrm{~mm}$. Areas of necrosis were excluded from the images (see Materials and Methods). 

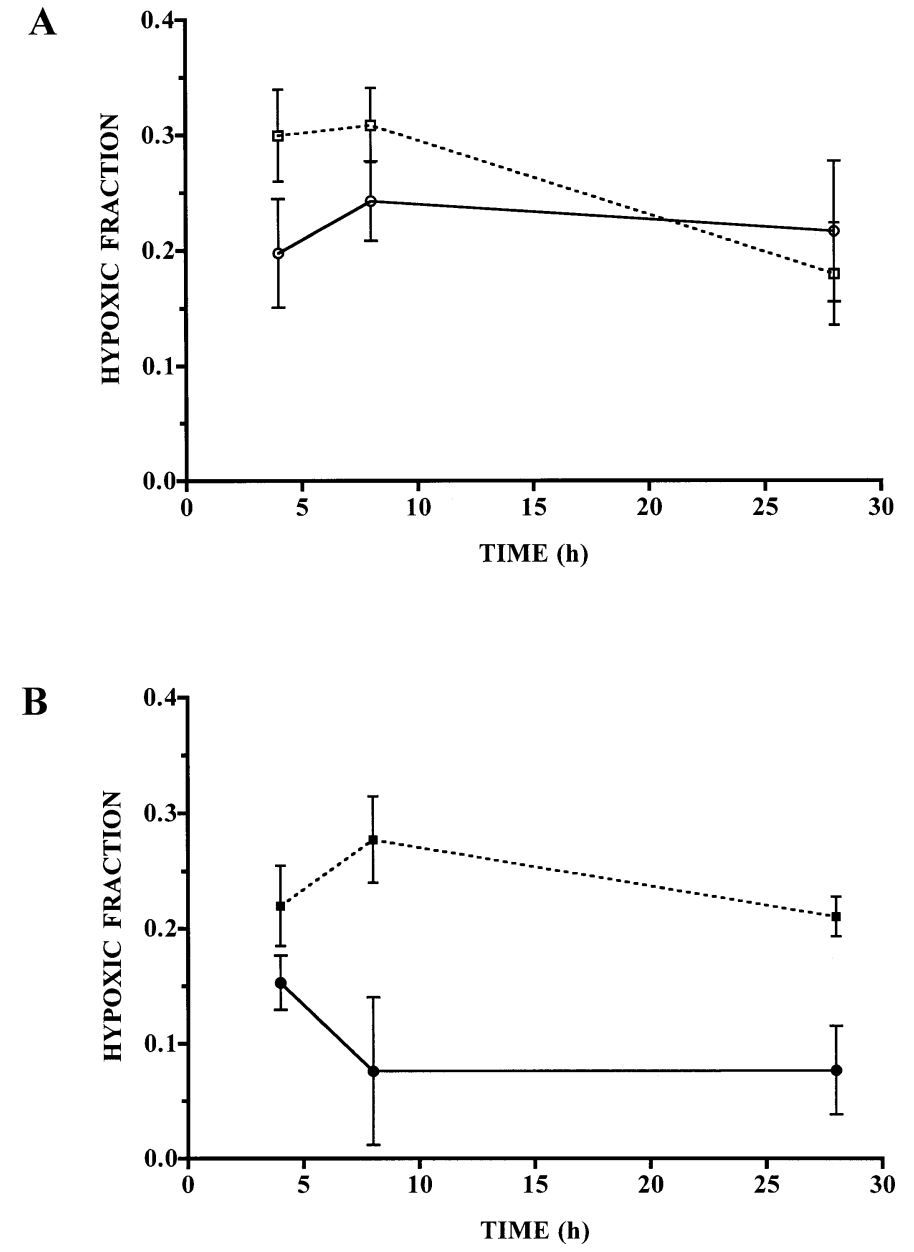

FIG. 3. Hypoxic fractions for the first hypoxia marker pimonidazole (squares) and the second hypoxia marker CCI-103F (circles) in (panel A) untreated tumors (open symbols) and (panel B) irradiated tumors (solid symbols). Error bars are means \pm SEM.

This was caused by the relatively high radiation dose and resulted in nonspecific staining of BrdUrd. Microscopic examination of viable tumor areas indicated an almost complete absence of proliferating tumor cells at these times. At $28 \mathrm{~h}$ after irradiation, the clearance of dead cells was almost complete (H\&E-stained sections, Fig. 4), and a rapid recovery of tumor cell proliferation was observed (Fig. 4, left panel). The BrdUrd labeling index (number of BrdUrd-labeled cells/total number of cells) was $16 \%$ (range 7-28) in the control tumors and 17\% (range 10-27) at $28 \mathrm{~h}$ after irradiation. However, at this time, the density of BrdUrdlabeled cells had decreased to $48 \%$ of the pretreatment value and the total cell density had decreased to 55\%. Thus, at $28 \mathrm{~h}$ after irradiation, the cell density had been reduced due to cell death, but the proportion of BrdUrd-labeled cells relative to the total number of viable cells had recovered to pretreatment levels (Fig. 4).

In unirradiated tumors, BrdUrd-labeled cells were found mainly in the proximity of the vessels. In contrast, at $28 \mathrm{~h}$ after irradiation, the distribution of proliferating cells was more random and was independent of distance from the vasculature. Furthermore, cells labeled with both the first hypoxia marker, pimonidazole (green), and the proliferation marker BrdUrd (red) were frequently observed at $28 \mathrm{~h}$ after irradiation, appearing as yellow dots within the pimonidazole-labeled area. A comparison with the double hypoxia marker staining showed that in general these cells were not labeled with the second hypoxia marker. Thus, upon improvement of the oxygenation status, a proportion of the initially hypoxic cells were labeled with BrdUrd.

\section{Radiation-Induced Apoptosis}

The right panels in Fig. 4 show apoptotic cells (activated caspase 3 , red) in relation to the first hypoxia marker (pimonidazole, green) and vasculature (white). In untreated tumors, approximately $95 \%$ of all apoptotic cells were located in pimonidazole-labeled areas and were situated near necrotic areas.

Radiation-induced cell death in tumors at 4 and $8 \mathrm{~h}$ after irradiation is illustrated in the $\mathrm{H} \& \mathrm{E}$-stained sections shown in Fig. 4. A substantial proportion of the irradiated cells had shrunk and contained condensed nuclei, which are morphological hallmarks of apoptosis. There was a significant threefold increase in the density of apoptotic cells (caspase 3 , Fig. 4 , right panels $)$ at both $4 \mathrm{~h}(P<0.001)$ and $8 \mathrm{~h}(P$ $<0.01$ ) after irradiation (Fig. 5). The increase in the density of apoptotic cells was about 10 -fold in tumor areas that were not hypoxic at the time of irradiation compared to a threefold increase in initially hypoxic regions (labeled with both pimonidazole and caspase 3). At $28 \mathrm{~h}$ after irradiation, the majority of the apoptotic cells had been cleared from the tissue and the density of apoptotic cells had returned to pretreatment levels in both the hypoxic and nonhypoxic cell populations. However, at this time, the cell density had decreased by about $50 \%$. Thus the relative number of apoptotic cells was still above control levels. In the control groups, an increase in the density of apoptotic cells was noted at $28 \mathrm{~h}$ in pimonidazole-stained areas (Fig. 5B). This can be explained by an accumulation of cells that had been hypoxic at the time of irradiation and were driven into apoptosis during the $28 \mathrm{~h}$ after pimonidazole injection. Cell debris labeled with pimonidazole was found in the necrotic areas and was excluded from the quantitative analysis. In Figs. 2 and 4, which show the resulting images after processing, these areas appear as black holes after the masking procedure.

\section{DISCUSSION}

\section{Kinetics of Hypoxic Cells}

In this study, both spatial and temporal changes in hypoxia were visualized in tumors after consecutive injection of two different bioreductive hypoxic cell markers. The hypoxia markers pimonidazole and CCI-103F are very similar and differ only in the immuno-recognizable side chain. Therefore, these markers label cells with similar oxygena- 


\section{Proliferation}
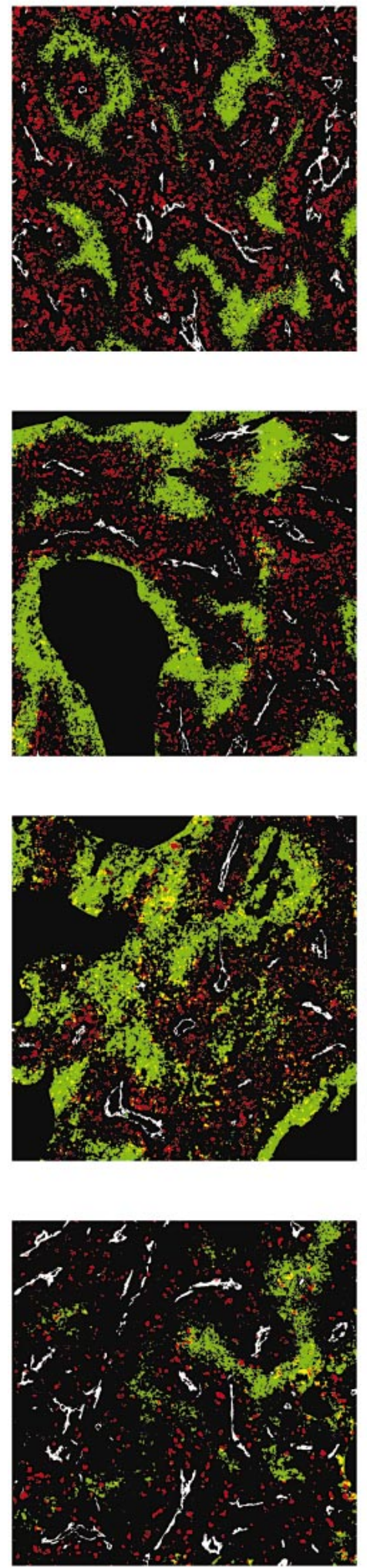

$\mathbf{H} \& \mathbf{E}$

\section{Unirradiated}
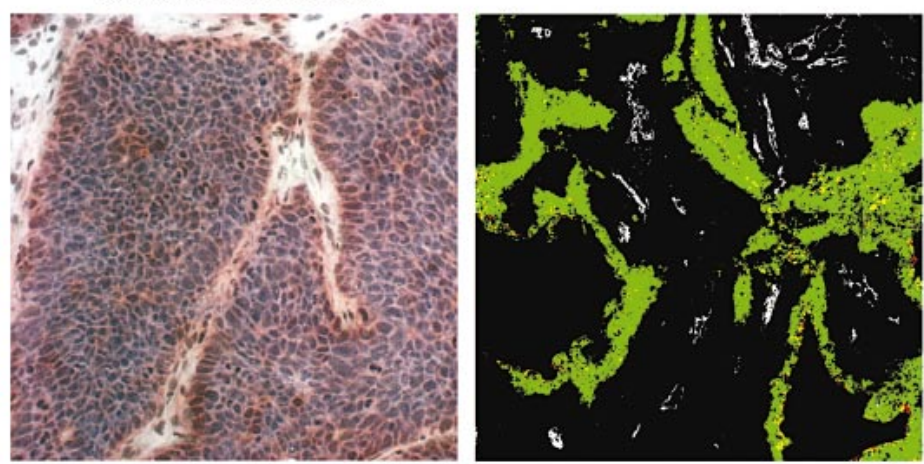

\section{4h RT}
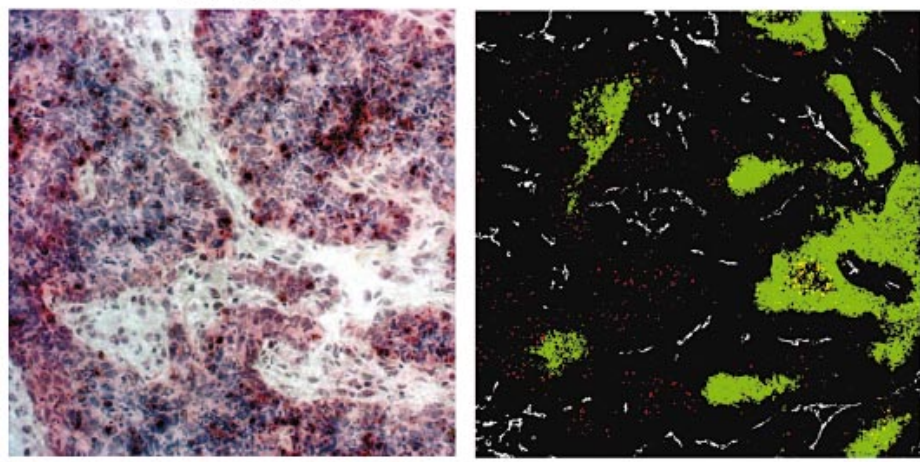

8h RT
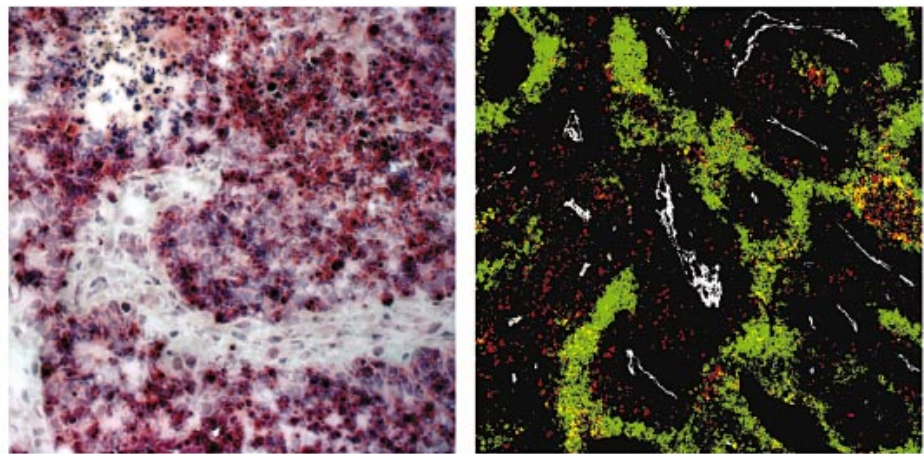

\section{8h RT}
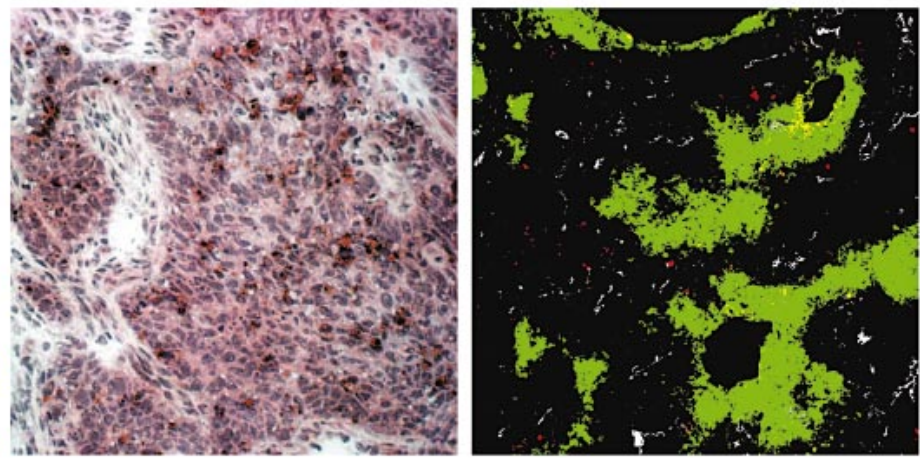

FIG. 4. The left panel shows details of composite binary images of vasculature (9F1, white), the first hypoxia marker (pimonidazole, green) given before and the proliferation marker (BrdUrd, red) given after irradiation. Overlap of proliferation and hypoxia is yellow. The middle panel shows H\&Estained sections of the same tumors. The right panel shows composite binary images of vasculature (9F1, white), the first hypoxia marker (pimonidazole, green), and apoptosis (activated caspase 3, red). Overlap of apoptosis and hypoxia is yellow. The top row shows untreated tumors with the same injection intervals of the markers as in tumors harvested $4 \mathrm{~h}$ after irradiation. The subsequent rows show tumors at 4,8 and $28 \mathrm{~h}$ after a single dose of $\mathrm{X}$ rays $(20 \mathrm{~Gy})$. Original magnification $200 \times$. Areas of necrosis were excluded from the images (see the Materials and Methods). 
A

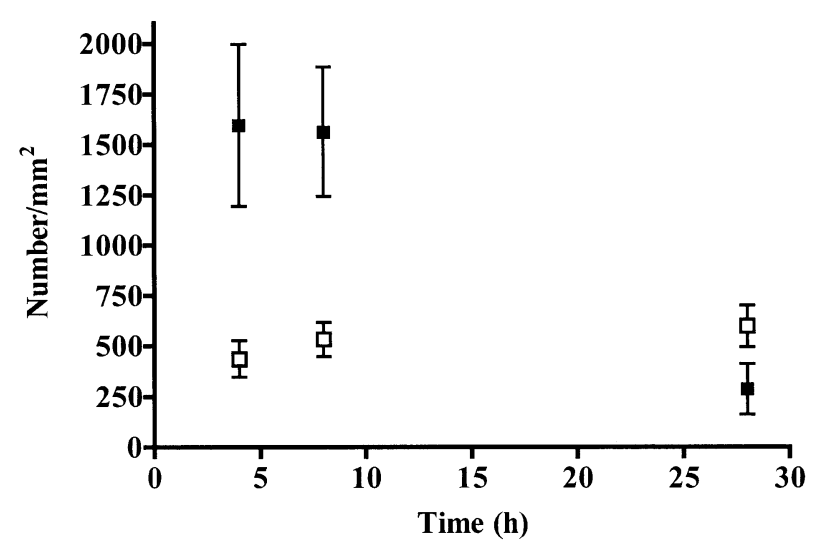

B

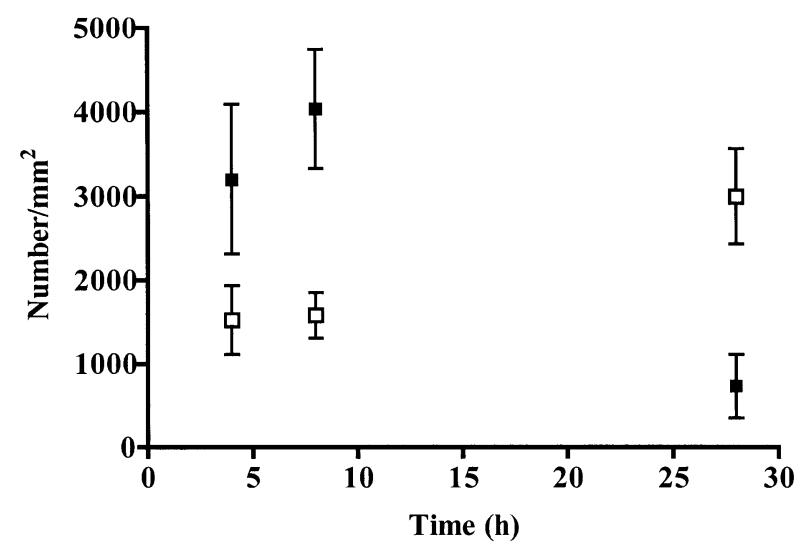

C

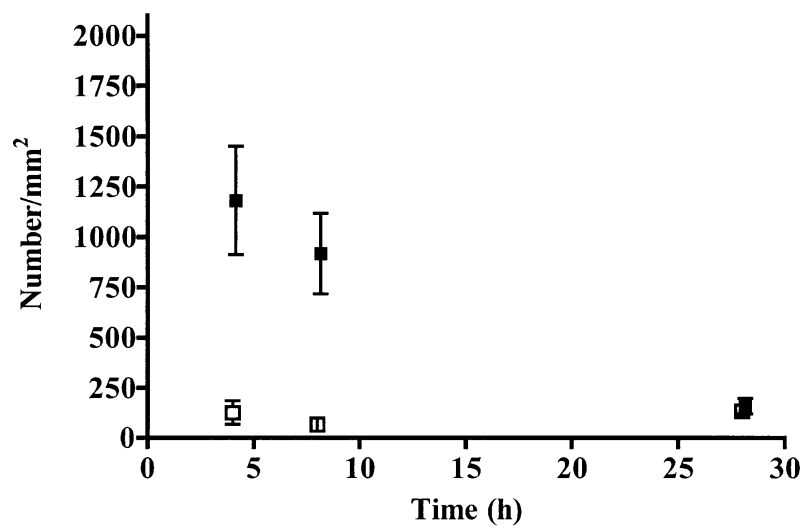

FIG. 5. Panel A shows overall density of apoptotic cells (number of apoptotic cells $/ \mathrm{mm}^{2}$ ) as function of time in irradiated tumors (solid squares) and control tumors (open squares). Panels B and C show the densities of apoptotic cells in the initially hypoxic and initially non-hypoxic tumor areas, respectively. tion status and can be visualized by immunohistochemical staining in the same tumor section without cross reactivity $(36,37)$.

In unirradiated tumors, CCI-103F was administered at fixed intervals before tumor harvest and pimonidazole was given at variable times before analysis. Without treatment, the decrease in pimonidazole at 8 and $28 \mathrm{~h}$ relative to the 4-h point was caused by clearance of cells that were hypoxic at the time of its injection (37). This is illustrated by the appearance of one or two cell layers labeled with only the second hypoxia marker (Fig. 2, red) at the vessel side of cells labeled with both hypoxia markers (yellow). The hypoxic cell turnover rate was heterogeneous throughout tumor sections, and regions with a slower hypoxic cell turnover were present in the tumor section shown in Fig. 2 (green only, unirradiated tumor section at $28 \mathrm{~h}$ ). Cell debris labeled with pimonidazole that appeared in the necrotic regions was excluded from analysis and in the images shown in Fig. 2. In previous studies, it was shown that large differences in the life span and turnover rate of hypoxic cells exist among different tumor lines $(37,43,50)$. It is also well known that radiation preferentially kills well-oxygenated cells, with a subsequent reoxygenation of the surviving cells. Therefore, it is likely that tumor-dependent kinetics of hypoxic cells affects the response to radiation.

One of the aims of this study was to analyze the kinetics of radiation-induced changes in hypoxic cells. In unirradiated tumors, the initially hypoxic cells were almost completely eliminated $28 \mathrm{~h}$ after injection. In contrast, after irradiation the hypoxic fraction based on pimonidazole staining did not decrease. If the initially hypoxic cell population was very radioresistant, an increase in the hypoxic fraction of pimonidazole-labeled cells compared to the total number of surviving tumor cells could be expected. However, at $28 \mathrm{~h}$ after irradiation, the cell density within the tumor surface had decreased, but the time until tumor harvest was too short to detect significant tumor shrinkage. Moreover, the hypoxic fraction was determined as the area of pimonidazole-labeled cells (initially hypoxic) divided by the total tumor area, irrespective of the number of cells. Therefore, a constant hypoxic fraction of pimonidazole-labeled cells before and after irradiation does not exclude an absolute increase in pimonidazole-labeled cells in irradiated tumors relative to the total number of surviving tumor cells.

After irradiation, the initially hypoxic (pimonidazole-labeled) cells were not labeled with the second hypoxia marker, CCI-103F, indicating a radiation-induced increase in the oxygenation of these cells. To exclude the possibility that irradiation had resulted in deficient intracellular reductases, a separate set of tumors were clamped at $28 \mathrm{~h}$ after irradiation. The intracellular reduction and binding are similar for all 2-nitroimidazoles (51-54), as are the spatial distributions of pimonidazole and CCI-103F $(36,55)$. Therefore, it was assumed that if pimonidazole could be reduced after irradiation, this would be similar for CCI-103F. Due to its more rapid accumulation and binding, pimonidazole was 
chosen as hypoxia marker for the clamping experiments. In the clamped and irradiated tumors, an intense pimonidazole labeling indicated that at $28 \mathrm{~h}$ after irradiation the tumor cells were well able to reduce 2-nitroimidazoles such as pimonidazole and CCI-103F.

The hypoxic fraction measured with the second hypoxia marker (CCI-103F) had decreased significantly at $8 \mathrm{~h}$ after irradiation and remained low for at least the subsequent 20 h. Comparison with the first hypoxia marker, pimonidazole, showed that the improvement of the oxygenation status was evenly distributed throughout the tumor section. In unperturbed C38 tumors, the hypoxic cell turnover rate is more rapid than the metabolism and clearance of reduced and bound pimonidazole (37). Moreover, a larger fraction of initially hypoxic cells was present in the tumor tissue $24 \mathrm{~h}$ after irradiation than at the same time in nonirradiated tumors. Therefore, it is unlikely that the present results were influenced by the rate of metabolism of reduced and bound drug. However, if the life spans of the hypoxic tumor cells exceed the time needed for metabolism and clearance of reduced and bound marker from the cells, the stability of the bound marker could affect the interpretation of data.

Binding of misonidazole and other 2-nitroimidazoles show a steep increase below $10 \mathrm{mmHg}$ with a $\mathrm{K}_{\mathrm{m}}$ around 1-2 mmHg, which is close to the $\mathrm{K}_{\mathrm{m}}$ of radioresistance, which usually falls between 2 and $4 \mathrm{mmHg}(44,48,56-$ $58)$. In addition, it has been shown that irradiation results in an increased oxygen tension $(28,49,59,60)$. Therefore, it can be concluded that the decrease in hypoxia marker staining after irradiation corresponds to an actual increase in oxygen tension (61).

Although neither erythrocyte delivery nor oxygen delivery was actually measured, it is likely that the majority of the Hoechst 33342-positive vessels were also subject to erythrocyte flow. However, plasma flow, defined as the presence of perfusion marker without accompanying red blood cell flux, has been reported in up to $9 \%$ of (predominantly small) vessels in the R3230AC mammary carcinoma (9). Therefore, the data in the current study suggest that in the C38 line, radiation did not affect tumor blood flow, but an effect on oxygen delivery could not be excluded. Thus irradiation resulted in a decreased elimination rate of initially hypoxic cells and an increased oxygen tension.

\section{Dynamics of Radiation-Induced Changes in Proliferation and Apoptosis}

At 4 and $8 \mathrm{~h}$ after irradiation, there was a threefold overall increase in apoptosis, which was as much as tenfold in initially non-hypoxic areas. This is in agreement with radiation-induced programmed cell death of relatively normally oxygenated and radiosensitive cells. The clearance of dead cells after irradiation seemed to be rapid since the density of apoptotic cells had returned to the level of that in unirradiated tumors within $28 \mathrm{~h}$. However, the total cell density had decreased by almost $50 \%$; therefore, the pro- portion of apoptotic cells relative to the total number of cells was still elevated compared to untreated tumors. This was in accordance with the qualitative analysis (Fig. 4) indicating that cell death after irradiation in this tumor line was mainly due to apoptosis. However, in our opinion, the presence of apoptotic lymphocytes or an effect of radiation on the turnover rate of apoptotic cells is unlikely but cannot be completely excluded.

The decrease in proliferation at 4 and $8 \mathrm{~h}$ after irradiation was clearly present upon visual assessment. However, there was an increased level of nonspecific staining in necrotic/ apoptotic cells induced by the relatively high radiation dose (H\&E-stained sections, Fig. 4). Therefore, it was not possible to distinguish viable proliferating cells in the binary images. Although the tumor sections at $8 \mathrm{~h}$ after irradiation appeared to be dominated by apoptotic cells, visual examination at higher magnification showed that each apoptotic cell was surrounded by several viable and intact cells. At $28 \mathrm{~h}$ after irradiation, quantitative analysis showed that the BrdUrd labeling index had returned to pretreatment levels, indicating that these cells either were proliferating ( $\mathrm{S}$ phase) or were subject to DNA repair. It is well known that a large radiation dose results in a $\mathrm{G}_{2}$ block ranging from 0.8-3.0 $\mathrm{h} / \mathrm{Gy}(62,63)$. Flow cytometry has shown that the duration of $\mathrm{S}$ phase is about $8 \mathrm{~h}$ in the $\mathrm{C} 38$ tumor (unpublished results). The maximal quantity of BrdUrd incorporated in repairing cells is profoundly less than the amount incorporated during replicative DNA synthesis. In the current study, the brightness of the BrdUrd signal intensity at $28 \mathrm{~h}$ after irradiation was similar to that in control cells. Considering the general length of $\mathrm{G}_{2} / \mathrm{M}$ blocks and the duration of $\mathrm{S}$ phase, it is likely that the majority of the BrdUrdlabeled cells observed at this time were in the first replicative $\mathrm{S}$ phase after irradiation. Many of the BrdUrd-labeled tumor cells may be doomed to die after one or two cell divisions. In addition, it has been shown that induction of apoptosis can occur in parallel with replicative DNA synthesis (64), resulting in BrdUrd labeling but not yet detectable features of apoptotic cells. Since we studied only the early kinetics after irradiation, effects due to apoptosis or doomed cells cannot be ruled out. In this study, the BrdUrd labeling index had returned to pretreatment levels at $28 \mathrm{~h}$ after irradiation, but the absolute number of labeled cells was still lower than in unirradiated tumors due to the decrease in cell density (H\&E staining, Fig. 4).

In contrast to untreated tumors, the distribution of proliferating cells was more random and was independent of the vasculature in irradiated tumors. In addition, the relative number of cells labeled with both BrdUrd and pimonidazole (Fig. 4, yellow dots) was higher than in control tumors. There could be a potential problem with delivery of BrdUrd in tumor cells, which could result in an underestimation of the proliferation rate. It has been argued that the dose generally used for in vivo labeling is too small to give maximal labeling at larger distances from the vasculature (65). However, the presence of different patterns of BrdUrd labeling 
among tumors argues against this. A histological pattern with a random distribution of proliferation was described with S-phase cells also present at larger distances from the vasculature (66). Also, the distance at which BrdUrd labeling still was present (200 $\mu \mathrm{m}$ from the vasculature) (4) indicates that the dose used is sufficient to label proliferating cells further away from the vasculature. However, there might be a risk of underestimation of the BrdUrd labeling around nonperfused (Hoechst-negative) blood vessels (67). In the current study, the proportion of functional (perfused) blood vessels was similar in both the controls and the irradiated tumors. Therefore, the difference in proliferation between controls and irradiated tumors can be only minimally affected by limitations in the delivery of BrdUrd. Those cells were not hypoxic at the time of harvest (negative for CCI-103F), indicating that, upon improved oxygen tension, irradiated hypoxic cells can be recruited back into active proliferation.

\section{Oxygen Delivery Relative to Oxygen Consumption after Irradiation}

The proportions of proliferating cells and hypoxic cells decreased and the number of apoptotic cells increased within 4 to $8 \mathrm{~h}$ after irradiation. Therefore, it is likely that the initial radiation-induced decrease in hypoxic fraction was caused by reduced cellular respiration. The nadir of hypoxia and proliferation was reached in parallel with the maximum number of apoptotic cells. This might be explained by low overall cellular respiration due to preferentially radiationinduced killing of the proliferating cell population (61). At $28 \mathrm{~h}$ after treatment, the level of apoptosis and the BrdUrdlabeling index was almost back to pretreatment levels while the amount of hypoxia remained low. Since radiation did not affect the perfused fraction or the vascular density, it is unlikely that the blood supply in C38 tumors was affected by radiation. The decreased overall cell density may explain the remaining improvement of the oxygen tension. In vivo-ex vivo analysis of the hypoxia marker $\mathrm{AF} 2$, a 5nitrofuran, showing increased diffusion distances after radiation provided evidence that the decrease in tumor cell hypoxia could be explained by decreased oxygen consumption (28). Our data were also in agreement with mathematical modeling indicating that a change in oxygen consumption can be relatively more important that an increase in oxygen delivery (68).

\section{Clinical Relevance}

In human head and neck tumors and xenografts, it has been shown that heterogeneities in patterns of tumor cell proliferation and hypoxia are present even in tumors with similar histo-pathological features $(4,40,66)$. In addition, tumor line-dependent differences in the hypoxic cell turnover rate of at least a factor of three were recently demonstrated (37). Temporary improvements in tumor $p \mathrm{O}_{2}$ after irradiation, ranging from hours to days, have been reported in different tumor models. Also, the time until a steadystate level of hypoxia was reached after irradiation differed between tumor models $(26-29,31,49)$. Although they were not observed in the current study, differences in the effects of radiation on tumor perfusion have been reported $(27,28$, 31, 59). Comparison of different studies may be influenced by methodological differences, but tumor line-dependent differences have been reported within the same study (29, 37). From the above-mentioned aspects, it can be concluded that differences in the response to anticancer treatments with respect to dynamics of hypoxia, proliferation and/or apoptosis are likely to exist among patients.

The use of a large single dose of 20 Gy may have its limitations, although such a dose is equivalent to a full curative clinical radiotherapy dose. Furthermore, it has been shown with radiobiological assays that reoxygenation can be detected after a single dose of $10 \mathrm{~Gy}(28,49)$. The C38 tumor line used in the current study has a high intrinsic cell loss factor (59\%), a high BrdUrd labeling index [24\% (flow cytometry)] (37) and a hypoxic fraction ranging from 13 to $34 \%$ (current study). Therefore, this is a hypoxic and probably radioresistant tumor line, which was the rationale for the large radiation dose. It is likely that a lower dose of $X$ rays would affect only the extent of the observed changes in the tumor microenvironment, but it is unlikely that this would affect the kinetics of the cellular responses to irradiation.

After fractionated treatments, improved tumor oxygenation has been measured since the effects of each fraction are cumulative $(69,70)$. For quantitative analysis (as performed in this study) of clinically relevant doses (2 Gy), several fractions would be required. However, between the delivered fractions, DNA repair and re-oxygenation occur and affect the subsequent dose, making a fractionated irradiation schedule difficult to interpret for studies of the kinetics of treatment induced cellular responses.

\section{Conclusion}

The oxygenation status of most tumor cells that were hypoxic at the time of a single dose of radiation (20 Gy) had improved at $8 \mathrm{~h}$ after treatment and remained unchanged over the subsequent $20 \mathrm{~h}$. After a temporary decrease in proliferation and increase in apoptosis, both parameters had almost returned to pretreatment levels $28 \mathrm{~h}$ after irradiation. The tumor blood perfusion was unaffected by radiation. These data indicate an increase in tumor oxygenation status after irradiation. The most likely explanation is a decrease in cellular respiration.

\section{ACKNOWLEDGMENTS}

We thank J. Lok and W. Peeters for excellent technical support and J. A. Raleigh, Department of Radiation Oncology, University of North Carolina, Chapel Hill, NC, for supplying CCI-103F and antibodies to CCI-103F and pimonidazole. We thank the Central Animal Laboratory for excellent animal care. Financial support was provided by the Dutch Cancer Society grant number 2003-2901. 
Received: July 20, 2005; accepted: October 28, 2005

\section{REFERENCES}

1. I. F. Tannock, The relation between cell proliferation and the vascular system in a transplanted mouse mammary tumour. Br. J. Cancer $\mathbf{2 2}$, 258-273 (1968).

2. D. G. Hirst and J. Denekamp, Tumour cell proliferation in relation to the vasculature. Cell Tissue Kinet. 12, 31-42 (1979).

3. J. Bussink, J. H. A. M. Kaanders, P. F. J. W. Rijken, C. A. Martindale and A. J. van der Kogel, Multiparameter analysis of vasculature, perfusion and proliferation in human tumour xenografts. Br. J. Cancer 77, 57-64 (1998).

4. A. S. E. Ljungkvist, J. Bussink, P. F. J. W. Rijken, J. H. A. M. Kaanders, A. J. van der Kogel and J. Denekamp, Vascular architecture, hypoxia, and proliferation in first-generation xenografts of human head-and-neck squamous cell carcinomas. Int. J. Radiat. Oncol. Biol. Phys. 54, 215-228 (2002).

5. R. H. Thomlinson and L. H. Gray, The histological structure of some human lung cancers and the possible implications for radiotherapy. Br. J. Cancer IX, 539-549 (1955).

6. P. Vaupel, F. Kallinowski and P. Okunieff, Blood flow, oxygen and nutrient supply, and metabolic microenvironment of human tumors: A review. Cancer Res. 49, 6449-6465 (1989).

7. K. I. E. M. Wijffels, J. H. A. M. Kaanders, P. F. J. W. Rijken, J. Bussink, F. J. van den Hoogen, H. A. M. Marres, P. C. M. de Wilde, J. A. Raleigh and A. J. van der Kogel, Vascular architecture and hypoxic profiles in human head and neck squamous cell carcinomas. Br. J. Cancer 83, 674-683 (2000).

8. E. M. Zeman, D. P. Calkins, J. M. Cline, D. E. Thrall and J. A. Raleigh, The relationship between proliferative and oxygenation status in spontaneous canine tumors. Int. J. Radiat. Oncol. Biol. Phys. 27, 891-898 (1993).

9. M. W. Dewhirst, H. Kimura, S. W. Rehmus, R. D. Braun, D. Papahadjopoulos, K. Hong and T. W. Secomb, Microvascular studies on the origins of perfusion-limited hypoxia. Br. J. Cancer 27 (Suppl.), S247-S251 (1996).

10. K. H. Pigott, S. A. Hill, D. J. Chaplin and M. I. Saunders, Microregional fluctuations in perfusion within human tumours detected using laser Doppler flowmetry. Radiother. Oncol. 40, 45-50 (1996).

11. M. Höckel and P. Vaupel, Tumor hypoxia: Definitions and current clinical, biologic, and molecular aspects. J. Natl. Cancer Inst. 93, 266-276 (2001).

12. E. K. Rofstad, Microenvironment-induced cancer metastasis. Int. J. Radiat. Biol. 76, 589-605 (2000).

13. M. B. Barton, T. J. Keane, T. Gadalla and E. Maki, The effect of treatment time and treatment interruption on tumour control following radical radiotherapy of laryngeal cancer. Radiother. Oncol. 23, 137-143 (1992).

14. A. Fyles, T. J. Keane, M. Barton and J. Simm, The effect of treatment duration in the local control of cervix cancer. Radiother. Oncol. 25, 273-279 (1992).

15. W. R. Lee, R. B. Marcus, Jr., M. D. Sombeck, W. M. Mendenhall, L. S. Morgan, D. E. Freeman and R. R. Million, Radiotherapy alone for carcinoma of the vagina: The importance of overall treatment time. Int. J. Radiat. Oncol. Biol. Phys. 29, 983-988 (1994).

16. H. R. Withers, J. M. Taylor and B. Maciejewski, The hazard of accelerated tumor clonogen repopulation during radiotherapy. Acta Oncol. 27, 131-146 (1988).

17. J. M. Taylor, H. R. Withers and W. M. Mendenhall, Dose-time considerations of head and neck squamous cell carcinomas treated with irradiation. Radiother. Oncol. 17, 95-102 (1990).

18. M. Saunders, S. Dische, A. Barrett, A. Harvey, D. Gibson and M. Parmar, Continuous hyperfractionated accelerated radiotherapy (CHART) versus conventional radiotherapy in non-small-cell lung cancer: A randomised multicentre trial. CHART Steering Committee. Lancet 350, 161-165 (1997).

19. J. Overgaard, H. S. Hansen, L. Specht, M. Overgaard, C. Grau, E.
Andersen, J. Bentzen, L. Bastholt, O. Hansen and J. F. Evensen, Five compared with six fractions per week of conventional radiotherapy of squamous-cell carcinoma of head and neck: DAHANCA 6 and 7 randomised controlled trial. Lancet 362, 933-940 (2003).

20. K. K. Fu, T. F. Pajak, A. Trotti, C. U. Jones, S. A. Spencer, T. L. Phillips, A. S. Garden, J. A. Ridge and K. K. Ang, A Radiation Therapy Oncology Group (RTOG) phase III randomized study to compare hyperfractionation and two variants of accelerated fractionation to standard fractionation radiotherapy for head and neck squamous cell carcinomas: First report of RTOG 9003. Int. J. Radiat. Oncol. Biol. Phys. 48, 7-16 (2000).

21. G. D. Wilson, S. Dische and M. I. Saunders, Studies with bromodeoxyuridine in head and neck cancer and accelerated radiotherapy. Radiother. Oncol. 36, 189-197 (1995).

22. D. M. Brizel, G. S. Sibley, L. R. Prosnitz, R. L. Scher and M. W. Dewhirst, Tumor hypoxia adversely affects the prognosis of carcinoma of the head and neck. Int. J. Radiat. Oncol. Biol. Phys. 38, 285-289 (1997).

23. A. Fyles, M. Milosevic, D. Hedley, M. Pintilie, W. Levin, L. Manchul and R. P. Hill, Tumor hypoxia has independent predictor impact only in patients with node-negative cervix cancer. J. Clin. Oncol. 20, 680687 (2002).

24. M. Höckel, K. Schlenger, B. Aral, M. Mitze, U. Schaffer and P. Vaupel, Association between tumor hypoxia and malignant progression in advanced cancer of the uterine cervix. Cancer Res. 56, 45094515 (1996).

25. J. H. A. M. Kaanders, K. I. E. M. Wijffels, H. A. M. Marres, A. S. E. Ljungkvist, L. A. M. Pop, F. J. A. van den Hoogen, P. C. M. de Wilde, J. Bussink, J. A. Raleigh and A. J. van der Kogel, Pimonidazole binding and tumor vascularity predict for treatment outcome in head and neck cancer. Cancer Res. 62, 7066-7074 (2002).

26. R. F. Kallman, The phenomenon of reoxygenation and its implications for fractionated radiotherapy. Radiology 105, 135-142 (1972).

27. J. Bussink, J. H. A. M. Kaanders, P. F. J. W. Rijken, J. A. Raleigh and A. J. van der Kogel, Changes in blood perfusion and hypoxia after irradiation of a human squamous cell carcinoma xenograft tumor line. Radiat. Res. 153, 398-404 (2000).

28. P. L. Olive, Radiation-induced reoxygenation in the SCCVII murine tumour: Evidence for a decrease in oxygen consumption and an increase in tumour perfusion. Radiother. Oncol. 32, 37-46 (1994).

29. R. Murata, Y. Shibamoto, K. Sasai, N. Oya, T. Shibata, T. Takagi and M. Abe, Reoxygenation after single irradiation in rodent tumors of different types and sizes. Int. J. Radiat. Oncol. Biol. Phys. 34, 859865 (1996).

30. M. J. Dorie and R. F. Kallman, Reoxygenation in the RIF-1 tumor Int. J. Radiat. Oncol. Biol. Phys. 10, 687-693 (1984).

31. N. Crokart, B. F. Jordan, C. Baudelet, R. Ansiaux, O. Sonveuax, V. Gregoire, N. Begheon, J. d. Wever, C. Bouzin and B. Gallez, Early reoxygenation in tumors after irradiation: Determining factors and consequences for radiotherapy regimens using daily multiple fractions. Int. J. Radiat. Oncol. Biol. Phys. 63, 901-910 (2005).

32. A. S. Kennedy, J. A. Raleigh, G. M. Perez, D. P. Calkins, D. E. Thrall, D. B. Novotny and M. A. Varia, Proliferation and hypoxia in human squamous cell carcinoma of the cervix: First report of combined immunohistochemical assays. Int. J. Radiat. Oncol. Biol. Phys. 37, 897-905 (1997).

33. B. M. Fenton, S. F. Paoni, B. K. Beauchamp and I. Ding, Zonal image analysis of tumour vascular perfusion, hypoxia, and necrosis. $\mathrm{Br}$. $J$. Cancer 86, 1831-1836 (2002).

34. I. J. Hoogsteen, H. A. M. Marres, K. I. E. M. Wijffels, P. F. J. W. Rijken, J. P. W. Peters, F. J. van den Hoogen, E. Oosterwijk, A. J. van der Kogel and J. H. A. M. Kaanders, Colocalization of carbonic anhydrase 9 expression and cell proliferation in human head and neck squamous cell carcinoma. Clin. Cancer Res. 11, 97-106 (2005).

35. S. M. Evans, S. Hahn, D. R. Pook, W. T. Jenkins, A. A. Chalian, P. Zhang, C. Stevens, R. Weber, G. Weinstein and C. J. Koch, Detection of hypoxia in human squamous cell carcinoma by EF5 binding. Cancer Res. 60, 2018-2024 (2000).

36. A. S. E. Ljungkvist, J. Bussink, P. F. J. W. Rijken, J. A. Raleigh, J. 
Denekamp and A. J. van der Kogel, Changes in tumor hypoxia measured with a double hypoxic marker technique. Int. J. Radiat. Oncol. Biol. Phys. 48, 1529-1538 (2000).

37. A. S. E. Ljungkvist, J. Bussink, P. F. J. W. Rijken, J. A. Raleigh, J. H. A. M. Kaanders and A. J. van der Kogel, Hypoxic cell turnover in different solid lines. Int. J. Radiat. Oncol. Biol. Phys. 62, 11571168 (2005).

38. H. W. M. van Laarhoven, J. Bussink, J. Lok, C. J. A. Punt, A. Heerschap and A. J. van der Kogel, Effects of nicotinamide and carbogen in different murine colon carcinomas: Immunohistochemical analysis of vascular architecture and microenvironmental parameters. Int. J. Radiat. Oncol. Biol. Phys. 60, 310-321 (2004).

39. G. D. Wilson, N. J. McNally, S. Dische, M. I. Saunders, C. Des Rochers, A. A. Lewis and M. H. Bennett, Measurement of cell kinetics in human tumours in vivo using bromodeoxyuridine incorporation and flow cytometry. Br. J. Cancer 58, 423-431 (1988).

40. K. I. E. M. Wijffels, J. H. A. M. Kaanders, H. A. M. Marres, J. Bussink, H. P. W. Peters, P. F. J. W. Rijken, P. C. M. de Wilde and A. J. van der Kogel, Patterns of proliferation related to vasculature in human head-and-neck carcinomas before and after transplantation in nude mice. Int. J. Radiat. Oncol. Biol. Phys. 51, 1346-1353 (2001).

41. G. J. Peters, J. Van Dijk, J. C. Nadal, C. J. Van Groeningen, J. Lankelma and H. M. Pinedo, Diurnal variation in the therapeutic efficacy of 5-fluorouracil against murine colon cancer. In Vivo 1, 113-117 (1987).

42. J. A. Raleigh, A. J. Franko, E. O. Treiber, J. A. Lunt and P. S. Allen, Covalent binding of a fluorinated 2-nitroimidazole to EMT-6 tumors in Balb/C mice: Detection by F-19 nuclear magnetic resonance at 2.35 T. Int. J. Radiat. Oncol. Biol. Phys. 12, 1243-1245 (1986).

43. C. Azuma, J. A. Raleigh and D. E. Thrall, Longevity of pimonidazole adducts in spontaneous canine tumors as an estimate of hypoxic cell lifetime. Radiat. Res. 148, 35-42 (1997).

44. G. E. Arteel, R. G. Thurman, J. M. Yates and J. A. Raleigh, Evidence that hypoxia markers detect oxygen gradients in liver: Pimonidazole and retrograde perfusion of rat liver. Br. J. Cancer 72, 889-895 (1995).

45. J. A. Raleigh, G. G. Miller, A. J. Franko, C. J. Koch, A. F. Fuciarelli and D. A. Kelly, Fluorescence immunohistochemical detection of hypoxic cells in spheroids and tumours. Br. J. Cancer 56, 395-400 (1987).

46. P. F. J. W. Rijken, J. P. W. Peters and A. J. van der Kogel, Quantitative analysis of varying hypoxic profiles in relation to functional vessels in different human glioma xenograft lines. Radiat. Res. 157, 626632 (2002).

47. P. F. J. W. Rijken, H. J. J. A. Bernsen, J. P. W. Peters, R. J. Hodgkiss, J. A. Raleigh and A. J. van der Kogel, Spatial relationship between hypoxia and the (perfused) vascular network in a human glioma xenograft: A quantitative multi-parameter analysis. Int. J. Radiat. Oncol. Biol. Phys. 48, 571-582 (2000).

48. J. A. Raleigh, S. C. Chou, G. E. Arteel and M. R. Horsman, Comparisons among pimonidazole binding, oxygen electrode measurements, and radiation response in $\mathrm{C} 3 \mathrm{H}$ mouse tumors. Radiat. Res. 151, 580-589 (1999).

49. I. H. Kim and J. M. Brown, Reoxygenation and rehypoxiation in the SCCVII mouse tumor. Int. J. Radiat. Oncol. Biol. Phys. 29, 493-497 (1994).

50. R. E. Durand and E. Sham, The lifetime of hypoxic human tumor cells. Int. J. Radiat. Oncol. Biol. Phys. 42, 711-715 (1998).

51. J. A. Raleigh, A. J. Franko, C. J. Koch and J. L. Born, Binding of misonidazole to hypoxic cells in monolayer and spheroid culture: Evidence that a side-chain label is bound as efficiently as a ring label. Br. J. Cancer 51, 229-235 (1985).

52. A. J. Varghese, Glutathione conjugates of misonidazole. Biochem. Biophys. Res. Commun. 112, 1013-1020 (1983).

53. E. Chacon, C. J. Morrow, A. A. Leon, J. L. Born and B. R. Smith,
Regioselective formation of a misonidazole-glutathione conjugate as a function of $\mathrm{pH}$ during chemical reduction. Biochem. Pharmacol. 37, 361-363 (1988).

54. J. A. Raleigh and C. J. Koch, Importance of thiols in the reductive binding of 2-nitroimidazoles to macromolecules. Biochem. Pharmacol. 40, 2457-2464 (1990).

55. K. L. Bennewith and R. E. Durand, Quantifying transient hypoxia in human tumor xenografts by flow cytometry. Cancer Res. 64, 61836189 (2004).

56. J. D. Chapman, A. J. Franko and J. Sharplin, A marker for hypoxic cells in tumours with potential clinical applicability. $\mathrm{Br}$. J. Cancer 43, 546-550 (1981).

57. M. W. Gross, U. Karbach, K. Groebe, A. J. Franko and W. Mueller Klieser, Calibration of misonidazole labeling by simultaneous measurement of oxygen tension and labeling density in multicellular spheroids. Int. J. Cancer 61, 567-573 (1995).

58. D. E. Thrall, M. C. McEntee, J. M. Cline and J. A. Raleigh, ELISA quantification of CCI-103F binding in canine tumors prior to and during irradiation. Int. J. Radiat. Oncol. Biol. Phys. 28, 649-659 (1994).

59. B. M. Fenton, E. M. Lord and S. F. Paoni, Effects of radiation on tumor intravascular oxygenation, vascular configuration, development of hypoxia, and clonogenic survival. Radiat. Res. 155, 360368 (2001).

60. M. J. Dorie and R. F. Kallman, Reoxygenation of the RIF-1 tumor after fractionated radiotherapy. Int. J. Radiat. Oncol. Biol. Phys. 12, 1853-1859 (1986).

61. S. Walenta and W. Mueller Klieser, Oxygen consumption rate of tumour cells as a function of their proliferative status. Adv. Exp. Med. Biol. 215, 389-391 (1987).

62. J. L. Schwartz, J. Cowan, D. J. Grdina and R. R. Weichselbaum, Attenuation of $\mathrm{G}_{2}$-phase cell cycle checkpoint control is associated with increased frequencies of unrejoined chromosome breaks in human tumor cells. Radiat. Res. 146, 139-143 (1996).

63. M. F. Smeets, E. H. Mooren and A. C. Begg, The effect of radiation on $\mathrm{G}_{2}$ blocks, cyclin $\mathrm{B}$ expression and cdc2 expression in human squamous carcinoma cell lines with different radiosensitivities. $R a$ diother. Oncol. 33, 217-227 (1994).

64. L. Zamai, E. Falcieri, P. Gobbi, S. Santi, M. Falconi, G. Marhefka and M. Vitale, Anti-BrdUrd labeling of newly synthesized DNA in HL-60 cells triggered to apoptosis. Cytometry 25, 324-332 (1996).

65. A. H. Kyle, L. A. Huxham, J. H. Baker, H. E. Burston and A. I. Minchinton, Tumor distribution of bromodeoxyuridine-labeled cells is strongly dose dependent. Cancer Res. 63, 5707-5711 (2003).

66. M. H. Bennett, G. D. Wilson, S. Dische, M. I. Saunders, C. A. Martindale, B. M. Robinson, A. E. O'Halloran, M. D. Leslie and J. H. Laing, Tumour proliferation assessed by combined histological and flow cytometric analysis: Implications for therapy in squamous cell carcinoma in the head and neck. Br. J. Cancer 65, 870-878 (1992).

67. H. L. Janssen, A. S. Ljungkvist, P. F. Rijken, D. Sprong, J. Bussink, A. J. van der Kogel, K. M. Haustermans and A. C. Begg, Thymidine analogues to assess microperfusion in human tumors. Int. J. Radiat. Oncol. Biol. Phys. 62, 1169-1175 (2005).

68. T. W. Secomb, R. Hsu, E. T. Ong, J. F. Gross and M. W. Dewhirst, Analysis of the effects of oxygen supply and demand on hypoxic fraction in tumors. Acta Oncol. 34, 313-316 (1995).

69. D. M. Brizel, S. P. Scully, J. M. Harrelson, L. J. Layfield, R. K. Dodge, H. C. Charles, T. V. Samulski, L. R. Prosnitz and M. W. Dewhirst, Radiation therapy and hyperthermia improve the oxygenation of human soft tissue sarcomas. Cancer Res. 56, 5347-5350 (1996).

70. E. Lartigau, A. Lusinchi, P. Weeger, P. Wibault, B. Luboinski, F. Eschwege and M. Guichard, Variations in tumour oxygen tension $\left(\mathrm{pO}_{2}\right)$ during accelerated radiotherapy of head and neck carcinoma. Eur. J. Cancer 34, 856-861 (1998). 